\title{
APRESENTAÇÃO
}

\section{Gêneros textuais nas abordagens do interacionismo sociodiscursivo e da sociorretórica: contribuições teóricas e práticas}

\author{
Genres under socio-discursive interactionism and \\ socio-rhetorical approaches: practical and theoretical \\ contributions
}

Lília Santos ABReu-TardeLl (UNESP)

Solange ARANHA (UNESP)

Esta edição da revista Delta contempla temáticas de grande relevância ao ensino de línguas, que são o ensino, a formação docente e a análise de textos compreendidos e estudados pela perspectiva dos gêneros textuais. Para isso, acreditamos ser fundamental unir duas perspectivas teóricas diferentes, pois esses três eixos nos quais se debruçam os artigos aqui selecionados trazem contribuições relevantes para estudiosos de linguagem e de gêneros sob qualquer perspectiva. Nesse sentido, lembramos a crítica de Matêncio, trazida pelas autoras do primeiro artigo aqui publicado, a de que falta "uma reflexão sistemática e consistente de como transformar os objetos de estudo produzidos no campo dos estudos da linguagem em objetos de ensino" (Matencio 2006: 96, apud Pereira, Basílio e Leitão, neste volume). Assim, as autoras, retomando Malu Matencio (2006), reforçam a falta de discussões acerca das práticas de letramento que vão além da organização dos diferentes gêneros textuais.

É essa lacuna que o artigo de Pereira, Basílio e Leitão, intitulado Artigo científico: um gênero textual caleidoscópico vem suprir. Nele, 
as autoras, a partir de uma experiência didática de produção de artigos científicos em uma disciplina aplicada, analisam os textos produzidos e defendem a necessidade de se redefinir o artigo científico a partir de constatações da relação dinâmica da escrita do artigo com outros gêneros tais como resenha, resumo e projeto de pesquisa, pois as mesmas figuras de ação são mobilizadas na escrita desses gêneros. Assim, a partir das atividades de retextualização do artigo científico oriundo de outros textos-base, as autoras propõem que as microações de linguagem identificadas sejam utilizadas como uma possível categoria de análise para investigar aspectos discursivos que possibilitam a singularidade da produção textual. As autoras apontam a necessidade de um ensino mais amplo do trabalho com a escrita e da intervenção consciente e planejada do professor para que o aluno seja inserido nas práticas linguageiras acadêmicas e que tenha consciência de suas microações de linguagem em sua escrita, propiciando, assim, o desenvolvimento dos conceitos científicos em relação ao gênero estudado. A partir da análise das microações de linguagem, as autoras acreditam ser possível avaliar não apenas o domínio das capacidades de linguagem, mas o grau de engajamento enunciativo do produtor. $\mathrm{O}$ caleidoscópio começa a se configurar na seção em que características principais do resumo, da resenha e do projeto de pesquisa enquanto componentes do artigo (e ao mesmo tempo independentes) são explorados pelas autoras através de pesquisadores de referência que já estudaram tais gêneros. Aúltima seção permite ao leitor visualizar o colorido do caleidoscópio através dos exemplos fornecidos. Esses exemplos evidenciam as microações de linguagem dos produtores dos textos empíricos e apontam para a necessidade de que o ensino da escrita voltado a uma prática de letramento acadêmico se deva voltar cada vez mais à integração entre o ensino de diferentes gêneros que, para usarmos as palavras das autoras, evidenciam o movimento caleidoscópico da produção acadêmica e que de forma alguma deve ser trabalhada de forma mecânica e prescritora.

Também sobre o ensino do gênero artigo científico, o texto Letramento acadêmico em francês: uma experiência de produção de artigos cientificos na área de estudos literários de Lousada, Barioni e Tonelli visa a apresentar o modelo didático desse gênero na língua francesa e a sequência didática elaborada para ensiná-lo. As autoras partem de uma experiência piloto para ensinar alunos de graduação em Letras -Francês que cursavam uma disciplina de Literatura que tinha como 
produto final a elaboração de um artigo científico. As autoras se filiam ao quadro teórico-metodológico do interacionismo sociodiscursivo (Bronckart, 1999), explicitam as características genéricas e propõem atividades práticas para desenvolver as capacidades de linguagem dos alunos, assim como descrevem o contexto em que a pesquisa foi realizada e os critérios de seleção dos exemplares analisados. Em seguida, as pesquisadoras apresentam as atividades que compõem a sequência didática elaborada a partir das análises e das dificuldades apresentadas nas primeiras versões entregues pelos alunos. Nas atividades apresentadas no artigo, as autoras focalizam a situação de produção, os aspectos textuais e a ficha de auto-avaliação. Como as próprias autoras apontam, há outros elementos do gênero não explorados na experiência piloto, apesar dos aspectos positivos salientados por elas, dentre eles, a evidente melhoria dos textos. Vale a pena destacar dois pontos do trabalho das autoras: a ficha de revisão, com a síntese dos principais erros linguísticos e estratégias para a auto-correção, o que colabora com o curto tempo disponível para se trabalhar o gênero em questão e o segundo, apontado pelas próprias autoras, que são as dificuldades de os alunos se colocarem no papel de pesquisadores e de formularem, portanto, perguntas de pesquisa próprias a partir das quais o artigo deve ser desenvolvido.

Nesse sentido, o artigo seguinte, O QNP e as dificuldades de construção do objeto de pesquisa: uma experiência de aprendizagem mediada sobre o gênero projeto de pesquisa, de Araújo, Dieb e Costa pode ajudar a preencher a lacuna que as autoras detectaram em sua prática. Os autores apresentam substancial contribuição para o ensino do projeto de pesquisa, um dos muitos gêneros acadêmicos que compõem o sistema de gêneros que circulam nas universidades e que implicam "habilidades no domínio dessa esfera discursiva quanto capacidade didática para apresentar aos alunos o raciocínio que permeia esse tipo de discurso". Os autores apresentam uma técnica chamada Quadro Norteador de Pesquisa (QNP) "como facilitadora da construção dos objetos de pesquisa tratados em projetos". Este quadro permite ao aluno "desenhar" previamente a pesquisa a ser desenvolvida por ele. Por meio deste instrumento mediador, o aluno tem apoio pedagógico para circular discursivamente nesta etapa da vida acadêmica na busca por compreender "as relações de interdependência existentes entre questão, hipótese e objetivo", e permitir ao "professor, que acompanha a construção desse 
objeto de pesquisa, um exercício de orientação mais eficiente e pontual a partir das dificuldades encontradas". O QNP é detalhadamente descrito para elucidar o leitor que pretenda utilizá-lo em suas aulas, com seus alunos, pois a técnica é "norteadora", o que implica "na alusão a uma bússola, pela qual o pesquisador poderá guiar-se sempre que se sentir inseguro em relação aos rumos de seu trabalho". Trata-se de uma proposta em constante evolução e intimamente ligada aos usuários e aos contextos de uso. Os resultados mostram três tipos de dificuldades apresentadas pelos alunos ao elaborarem seus quadros, i.e., dificuldades de aprender conceitos, dificuldades em planejar com coesão (unidade) os eixos do quadro e dificuldades no domínio da linguagem acadêmica. A reelaboração dessas dificuldades e as discussões por elas geradas é o ponto principal da pesquisa e da validação da técnica como poderoso instrumento mediador da aprendizagem em nível acadêmico.

Se são necessários estudos sobre as práticas linguageiras nos processos de letramento acadêmico, também o é entender o papel atribuído ao professor pela mídia nacional nos mais diversos gêneros, pois o professor é prisma fundamental nos processos de letramento. Nesse sentido, a proposta de Figueiredo e Bonini, em artigo intitulado Recontextualização e sedimentação do discurso e da prática social: como a mídia constrói uma representação negativa para o professor e para a escola pública, contempla a Análise Crítica do Gênero proposta por um dos autores e por outros pesquisadores em LA, cuja episteme é a Análise Crítica do Discurso, proposta por Fairclough (1992), acrescida de uma teoria de gênero, "de modo que o gênero passa a ser lido como parte da semiose social e como instância de realização da prática social". Por meio dela, os autores mostram como a mídia representa fragilmente o professor, a partir de uma cadeia de recontextualizações, como "perdedor, coitado, pobre, com baixo status social, um profissional que exerce seu ofício quase sempre em condições precárias de trabalho (em escolas representadas como 'zonas de guerra' e de abandono)." Os exemplos são provenientes de diversos suportes e gêneros que denotam a prática social recorrente e marcada contextual e historicamente. Infelizmente, os exemplos abundam por todo o país e reforçam jocosamente a atividade docente e o fazer profissional do professor. "Esses textos recontextualizam, para o público leigo, as práticas e a imagem dos professores, gerando representações amplamente disseminadas, naturalizadas e legitimadas 
que não só desregulam e demonizam a escola pública, como também desestimulam a docência como carreira para jovens brasileiros e, o que é pior, enfraquecem profissional e politicamente o professor, que é retirado do centro da construção de sua prática e da construção social da própria escola". O processo de recontextualização é trazido pelos autores porque "todo discurso recontextualiza práticas sociais" e o argumento central é o de que o trabalho docente é pejorativamente recontextualizado em diferentes suportes midiáticos. Os autores afirmam que "a mídia jornalística (utilizando cadeias de representações e reconstruções ramificadas e naturalizadas do ofício do professor) faz parte do aparato de relações de poder não como forma de repressão ou autoritarismo, mas como um lócus de criação de supostas 'verdades' sobre a escola e a docência que circulam no espaço público com forte poder de convencimento sobre os leitores/telespectadores/internautas, incluindo o próprio professorado". Nesse caso, os discursos servem como recursos para representar as práticas em gêneros diversos. E a partir desses gêneros é possível reconstruir as práticas representadas e os discursos que as subjazem.

Assim como o professor é fundamental no processo de ensino e aprendizagem dos estudantes, merece atenção e estudo o contexto e cursos em que esses alunos se inserem. O trabalho de Ramos, Gênero, IFA e design de cursos: relato de uma experiência, traz um questionamento sobre a elaboração de cursos de leitura em nível acadêmico que contemplem os gêneros textuais e não só cursos com cunho estratégico como atualmente divulgado e aplicado nas universidades. A proposta busca relatar a experiência de trazer para a prática pedagógica a utilização de gêneros escritos acadêmicos, apresentando o desenho e a implementação de um curso de compreensão escrita de Inglês para Fins Acadêmicos - IFA, e discutindo os problemas e as soluções encontrados nessa tarefa. Trata-se de uma proposta que alia os estudos em Inglês para Fins Específicos, os estudos de gêneros de diferentes correntes teóricas, a proposta de Graves (2000) para desenho de cursos e a proposta pedagógica da própria autora. Por meio da descrição histórica da implantação e reelaboração do curso, a autora pontua as mudanças teóricas e metodológicas que levaram o grupo criador e executor do argumento a reavaliarem os conteúdos e as formas de aplicação com vistas a um contexto mais propício para a aprendizagem e mais condizente com as necessidades contemporâneas. O detalhamento das etapas 
deve ajudar leitores interessados em propor cursos e conscientizar futuros professores sobre pontos fulcrais da teoria ao elaborarem cursos e repensarem suas práticas.

Dois artigos dessa coletânea se voltam para análises de gêneros e reflexões sobre os mesmos. Um deles é o artigo de Miranda, intitulado Análise interlinguística de gêneros textuais: contribuições para o ensino e a tradução, que propõe a análise de gêneros em uma perspectiva comparativa interlinguística. Filiando-se ao interacionismo sociodiscursivo e utilizando-se de dados gerados por projetos de pesquisa em Portugal e na Argentina, a autora apresenta o conceito de gênero tal como tomado pelo interacionismo sociodiscursivo e a importância do estudo de gêneros para se "desenvolver qualquer estudo sobre as práticas sociais de linguagem ou sobre as formas linguísticas". Miranda propõe a ampliação da análise de gêneros para outros campos, apresentando resultados de diferentes pesquisas já feitas nas duas línguas e que evidenciam que "os traços singulares dos gêneros se ligam mais às práticas sociais do que a liberdades ou restrições dos sistemas linguísticos". A autora aponta ainda três potencialidades que os estudos comparados podem trazer: (i) "a identificação de áreas críticas para a aprendizagem de línguas e para a tradução; (ii) a elaboração de materiais didáticos (para o ensino das línguas e para a formação dos tradutores) e de materiais auxiliares (para os professores e para os tradutores) e (iii) a identificação de critérios para as situações de avaliação de capacidades de linguagem". Miranda conclui a necessidade de se construir "modelos comparados de gêneros" para o ensino e para a tradução.

O outro é o artigo Um estudo do gênero abstract na disciplina de Antropologia: a heterogeneidade da(s) área(s), de Gil e Aranha que traz importante contribuição para os estudos do gênero abstract/ resumo por meio de uma análise focada na mesma área científica, a Antropologia, mas que apresenta resumos diferentes dependendo da filiação das subáreas ao continuum entre "ciências moles" e "ciências duras". As autoras afirmam "As disciplinas humanas podem ser mais próximas de disciplinas exatas do que de outra disciplina humana, dependendo da sua orientação e do seu recorte de pesquisa, aumentando, assim, a flexibilidade na forma de se ver as disciplinas e suas fronteiras com outras". Uma análise linguística aliada a uma análise de gênero como ação social (Miller, 2012), que modifica o contexto e é por ele 
modificado mostra a influência dos fazeres científicos na materialidade do texto e do gênero. Por meio da análise de movimentos retóricos de resumos em duas revistas da área de Antropologia, as autoras demonstram que a recorrência de cada um é diferente e indicam a relevância de cada informação para a referida área. As autoras concluem que "todas as disciplinas são heterogêneas em sua natureza; não são, por consequência, orientadas por apenas uma teoria, uma metodologia e uma forma de fazer pesquisa."

Os três artigos que completam a publicação vão na direção do letramento na escola de ensino básico e se voltam para questões também relevantes e carentes de maiores pesquisas, que são: o aspecto do ensino gramatical articulado ao gênero, o gênero resumo voltado o público de ensino médio técnico-integrado e o estudo de gestos didáticos ao se trabalhar com sequências didáticas de gêneros em um processo de formação docente aliada ao ensino e aprendizagem dos alunos.

No artigo Gramática/análise linguística no ensino de inglês (língua estrangeira) por meio da sequência didática: uma análise parcial, Pontara e Cristóvão discutem as possibilidades de articulação entre o ensino de gramática/análise linguística e de expressão escrita durante o processo de implementação de uma Sequência Didática por meio de alguns gêneros utilizados para o ensino de língua inglesa (comics, comic strips e political cartoon) em um centro de línguas no Estado do Paraná. As autoras adotam a concepção terminológica das gramáticas implícita, explícita e reflexiva, justificando tal adoção pela relação que pode ser estabelecida entre esses tipos de gramática e a as atividades linguísticas, epilinguísticas e metalinguísticas. As autoras defendem que todo o trabalho de análise linguística "acaba se constituindo também como um trabalho de gramática contextualizada". As autoras acreditam que aliar o trabalho proposto pelas sequências didáticas do grupo de Genebra (Schneuwly, Dolz, 2004) à proposta da análise linguística apresentada por alguns autores brasileiros, propiciaria um ensino de gramática. As autoras elencam os elementos linguístico-discursivos característicos dos gêneros trabalhados nas sequências didáticas e as dimensões linguístico-discursivas ensináveis dos gêneros por elas estudados. Finalizam apresentando um quadro relacionando as atividades da SD e seus conteúdos e a relação com a análise linguística, englobando nela os tipos de atividades e a relação com os tipos de 
gramática. As autoras concluem que a utilização da sequência didática possibilita um trabalho com a gramática na perspectiva da análise linguística, evidenciando que o ensino por meio dos gêneros textuais não minimiza o trabalho com a língua, mas "abre espaços para que o ensino da gramática continue acontecendo".

$\mathrm{O}$ artigo de Souza, Modelo de estrutura retórica para leitura e escrita de resumo escolar no ensino médio técnico, aborda um gênero pouco compartilhado nos meios acadêmicos porque geralmente fica restrito ao ambiente escolar em nível médio e ou técnico-integrado: o resumo escolar de reportagem. A autora salienta a ausência de referências para se trabalhar o resumo com essas características, já que são diferentes daqueles em nível universitário e dos escritos para congressos ou artigos, por exemplo. Por meio de uma análise dos resumos escolares que circulam no Ensino Médio Técnico Integrado e que são considerados pelos docentes desse contexto como adequados aos propósitos, a autora apresenta um modelo retórico-discursivo para ensino deste gênero dentro da disciplina de Metodologia Científica. Essa proposta é desenvolvida com base nos estudos sócio-retóricos de Swales (1990) no que concerne ao uso de movimentos e passos para o ensino pedagógico do gênero. A preocupação da autora com o contexto no qual atua e com as necessidades daquele público específico fica evidente porque apresenta uma triangulação de dados que contempla as necessidades do aluno, as exigências dos professores e as demandas retórico-discursivas do gênero a ser ensinado. A aplicação da proposta sócio-retórica desenvolvida pela autora se mostrou eficiente, pois permitiu que os alunos escrevessem textos mais próximos do que era esperado pelos outros professores (potenciais leitores desse gênero) e lhes deu maior autonomia para circular no ambiente escrito como autores e não apenas como reprodutores de modelos. Segundo a autora, os resultados indicam "que os participantes cumpriram satisfatoriamente a atividade, experimentando a estrutura retórica e se arriscando no uso dos recursos linguístico-discursivos para realizarem os movimentos retóricos e articulá-los".

No artigo de Barros e Gonçalves, Mediações formativas na aula de língua portuguesa: gestos didáticos numa concepção interacionista de ensino, é apresentado o resultado de uma pesquisa voltada para o uso da sequência didática como instrumento mediador do ensino da 
língua e na mobilização de gestos didáticos fundadores e específicos do agir docente. Os autores fundamentam-se na aula enquanto gênero da atividade docente e nos gestos didáticos como instrumento mediador da atividade, articulando-os a instrumentos que a corporificam, e analisam a transposição didática interna de um objeto específico de uma Sequência Didática da Carta de Reclamação. Os autores afirmam que a 'atividade de ensino perde muito por fechar dentro da sala de aula os "modos de fazer" de seu ator principal: o professor. Principal, pois é em torno dele que a atividade de ensino se concretiza, é ele que seleciona objetos e instrumentos didáticos, que mobiliza metodologias para que os objetos de ensino possam ser transformados em objetos apreendidos. Salientam a necessidade de esses "modos de fazer" serem compartilhados a fim de serem validados pela coletividade. Assim, os autores analisam as formas de agir de um professor iniciante e constatam que essas formas de agir "não se relaciona a coerções formalizadas da profissão, mas a regulações internas, motivadas pelas necessidades contextuais". Segundo os autores, são os gestos didáticos, juntamente com os instrumentos didáticos, que vão "corporificar" a atividade docente. A partir da definição e adoção do conceito de gestos didáticos fundadores e específicos, os autores analisam uma aula em que é aplicada uma sequência didática da carta de reclamação elaborada durante o processo de investigação, objetivando articular a formação docente com o processo de ensino e aprendizagem. Os autores, assim, procuram analisar o desenvolvimento das atividades e tarefas e o agir do professor, representados pelos gestos didáticos (verbais e não verbais) acionados durante a realização do gênero da atividade aula, verificando quais gestos didáticos específicos emergem no agir docente e a partir dos gestos fundadores. Barros e Gonçalves concluem que "o trabalho com SD requer não apenas o domínio do docente no gênero que está sendo didatizado, mas de outras práticas linguageiras que podem dialogar, seja por semelhanças, seja por diferenças com o gênero focalizado", necessitando, para isso, a mobilização de gestos didáticos específicos que "deem conta dos vários subobjetos de ensino que vão emergindo do objeto unificador da SD, muitas vezes não planificados no projeto de ensino".

Acreditamos que os artigos aqui selecionados, resultado de trabalhos desenvolvidos por pesquisadores de diferentes regiões do Brasil (Nordeste, Centro-Oeste, Sudeste e Sul) e também da Argentina 
evidenciam a importância que os estudos de gêneros apresentam no cenário nacional e internacional, seja no desenvolvimento de pesquisas de âmbito teórico seja do ponto de vista didático, contribuindo para os processos de letramento acadêmico nos diferentes níveis de ensino e para a formação docente de futuros profissionais.

Recebido em: 01 de junho de 2016 Aprovado em: 01 de julho de 2016

E-mails: lilia@ibilce.unesp.br solangeibilce@gmail.com

\section{Referências bibliográficas}

BronCKart, Jean Paul. 1999. Atividade de linguagem, textos e discursos. Por um interacionismo sócio-discursivo. Trad. Anna Rachel Machado, Pericles Cunha. São Paulo: Educ.

Fairclough, Norman. 1992. Discourse and social change. Cambridge: Polity Press.

Graves, Kathleen. 2000. Designing Language Courses: a guide for teachers. Londres: Heinle\&Heinle.

MATENCIO, Maria de Lourdes Meirelles. 2006. Letramento na formação do professor - integração a práticas discursivas acadêmicas e construção da identidade profissional. In: CorrêA, Manoel Luiz Gonçalves \& Boch, Françoise (Orgs.). Ensino de Língua: representação e letramento. Campinas, SP: Mercado de Letras. p. 93-105.

Miller, Carolyn. 2012. Gênero como ação social. In: Dionísio, A. P.; HoffnAgel, J. (org.). Gênero textual, agência e tecnologia: estudos. São Paulo: Parábola Editorial. p. 21-41.

Schneuwly, Bernard; Dolz, Joaquim. 2004. Gêneros orais e escritos na escola. Trad. e org. Roxane Rojo e Glaís Sales Cordeiro. Campinas: Mercado de Letras.

Swales, John. 1990. M. Genre Analysis: English in academic and research settings. 12 ed. Cambridge: Cambridge University Press. 